\title{
Probiotic Properties of Yeasts Isolated from Chicken Feces and Kefirs
}

\author{
KATARZYNA RAJKOWSKA* and ALINA KUNICKA-STYCZYŃSKA
}

Technical University of Łódź, Institute of Fermentation Technology and Microbiology, Łódź, Poland

Received 23 January 2010, revised 25 October 2010, accepted 28 October 2010

\begin{abstract}
The probiotic potential of 3 yeasts strains of Saccharomyces cerevisiae isolated from kefirs and feces was investigated and compared with 3 isolates from medicines and 2 collection strains (ATCC) of Saccharomyces cerevisiae var. boulardii. Genetic identification of yeasts based on karyotypes indicated their affiliation to Saccharomyces spp. although chromosomal polymorphism was observed. Concerning probiotic characteristics survival in simulated gastric and intestinal environment were examined. The survival of all tested yeasts in medium of $\mathrm{pH} 2.5$ was comparable and equaled $86.8-97.1 \%$ after 8 hours of incubation at $37^{\circ} \mathrm{C}$. The fecal isolate, probiotic and collection yeasts showed also high resistance to $\mathrm{pH} 1.5$ and their survival was $85.3-92.1 \%$, whereas for kefir strains it amounted to 33.1 and $38.9 \%$. All yeasts tested demonstrated high resistance to synthetic bile salts as well. In the presence of $0.1 \%$ sodium cholate and sodium deoxycholate the reduction of cell number by only $1 \log$ unit after 4 hours of incubation at $37^{\circ} \mathrm{C}$ was observed. However, $1.0 \%$ addition of ox bile did not affect their viability. In simulated gastric and intestinal environment survival of fecal, probiotic and collection strains was $86.3-93.7 \%$ after 4 hours of incubation in media with addition of $3 \mathrm{~g} / 1$ pepsin and $1 \mathrm{~g} / 1$ pancreatin. Kefir isolates were more sensitive to these conditions and a further $10 \%$ reduction of cell number in relation to probiotic yeasts was observed. The tested strains, except for kefir isolates, were able to grow at $37^{\circ} \mathrm{C}$. All the tested strains survived in sufficient number to create the possibility of proper action in the human body, although fecal, probiotic and collection strains tolerated the conditions of the human gastrointestinal tract better than food-borne yeasts.
\end{abstract}

K e y w ords: karyotype, probiotic yeasts, survival in human gastrointestinal tract

\section{Introduction}

Probiotic yeasts are non-pathogenic strains belonging to the species Saccharomyces cerevisiae var. boulardii (Ouwehand et al., 2002). Probiotic cultures have been used as both a preventive and therapeutic agent for the treatment of a variety of diarrheal diseases. S. cerevisiae var. boulardii is reported to be effective in the treatment for diarrhea in adults and children infected with Clostridium difficile, for diarrhea in human immunodeficiency virus-infected patients and for acute and chronic diarrhea in children and adults (McFarland and Bernasconi, 1993; Ouwehand et al., 2002). Potential mechanisms of their probiotic activity are based on secretion of proteases or inhibitory proteins, stimulation of immunoglobulin A, acquisition and elimination of secreted toxins (Fooks and Gibson, 2002; McFarland and Bernasconi, 1993).

A set of selection criteria considered to be relevant for any probiotic microorganism has been proposed by
Ouwehand et al. (1999). Tolerance to low $\mathrm{pH}$ and bile salts is seen as a prerequisite for strain survival through the gastrointestinal tract. Probiotics must be also able to resist to certain local stresses such as the presence of gastrointestinal enzymes, organic acids and temperature $37^{\circ} \mathrm{C}$ (Conway, 1996; Ouwehand et al., 1999).

The taxonomic characterization of Saccharomyces cerevisiae var. boulardii is still controversial. On the basis of molecular typing techniques this group of yeasts was initially identified as a separate species of the genus Saccharomyces i.e. Saccharomyces boulardii (McFarland, 1996). However, the development of molecular phylogenetics has led to changes in the classification of many yeast species (Liti et al., 2006; Vaughan-Martini, 2003). Using comparative genomic hybridizations for whole-genome analysis S. boulardii and $S$. cerevisiae were reported as members of the same species (Edwards-Ingram et al., 2004). In this context, the question appears if other $S$. cerevisiae strains demonstrate probiotic features as well.

* Corresponding author: K. Rajkowska, Technical University of Łódź, Institute of Fermentation Technology and Microbiology, Wólczańska 171/173, 90-924 Łódź; phone (0-42) 6313470; fax (042) 6365976; e-mail: katarzyna.rajkowska@p.lodz.pl 
In the present study, yeasts isolated from fermented milk products and chicken feces have been examined to evaluate their potentially probiotic properties. They have been classified taxonomically and compared to other Saccharomyces spp. strains of evidenced probiotic activities.

\section{Experimental}

\section{Materials and Methods}

Yeast strains. Two strains isolated from two different kefirs (S11, S12) and one strain isolated from chicken faces (S10) were examined and compared with three probiotic strains isolated from medicines: Enterol ${ }^{\circledR} 250$ Biocodex, Hamadin ${ }^{\circledR} \mathrm{N}$ Dr. Willmar Schwabe, Omniflora ${ }^{\circledR}$ Akut Novartis and Saccharomyces cerevisiae var. boulardii MYA-796, MYA-797 originated from the American Type Culture Collection. Yeasts were kept on YPD (1\% yeast extract, $2 \%$ peptone, $2 \%$ dextrose) agar slants and maintained at $-20^{\circ} \mathrm{C}$ in YPD broth containing $20 \%(\mathrm{v} / \mathrm{v})$ glycerol.

Analysis of chromosomal DNA. Chromosomes of yeast strains were isolated and separated by pulsedfield gel electrophoresis PFGE. The typical conditions for preparation of chromosomal DNA from the Saccharomyces yeasts were followed (Schwarz and Cantor, 1984). Yeast chromosomes were separated with a CHEF-DR II apparatus (Bio-Rad) in TBE buffer (Sigma) at $10^{\circ} \mathrm{C}$ and an interpolation of pulsed time of $110-120 \mathrm{~s}$ for 26 hours. The gel was stained in ethidium bromide for visualization of nuclear DNA. A standard set of $S$. cerevisiae YNN 295 chromosomes was obtained commercially (Bio-Rad) and used for comparison.

Tolerance to low pH. Cultures activated by two transfers in liquid YPD were centrifuged $(3000 \times \mathrm{g}$, $10 \mathrm{~min}, 4^{\circ} \mathrm{C}$ ) and cells were resuspended in sterile phosphate buffered saline PBS $(0.8 \%$ sodium chloride, $0.02 \%$ potassium chloride, $0.144 \%$ disodium phosphate, $0.024 \%$ potassium phosphate, $\mathrm{pH} 7.4)$. Low $\mathrm{pH}$ tolerance was estimated by inoculating $\left(10^{6} \mathrm{cfu} / \mathrm{ml}\right)$ activated cultivates into PBS with $\mathrm{pH}$ adjusted at 1.5 and 2.5 with $3 \mathrm{~N} \mathrm{HCl}$. The samples were incubated at $37^{\circ} \mathrm{C}$ and the number of viable cells was determined by the count plate method after 1, 2, 3, 4, 6 and 8 hours of incubation. The results are given as the mean value of three replicates and expressed as percentage log survival, calculated according to Williamson and Johnson (1981):

Percentage $\log$ survival $=\left(\log \mathrm{N} / \log \mathrm{N}_{0}\right) \times 100$ where $\mathrm{N}$ - count $(\mathrm{cfu} / \mathrm{ml})$ after incubation, $\mathrm{N}_{0}-$ count at time $0(\mathrm{cfu} / \mathrm{ml})$.

Bile tolerance. Cultures activated as described above were inoculated into liquid YPD medium supplemented with $0.1 \%$ and $1.0 \%$ mixture of synthetic bile salts $(50 \%$ sodium cholate and $50 \%$ sodium deoxycholate). Bile tolerance was also evaluated in liquid YPD medium with addition of $0.1 \%$ and $1.0 \%$ ox gall. The number of yeast cells was estimated by the count plate method after 20,40,60,120, 180 and 240 minutes of incubation at $37^{\circ} \mathrm{C}$. The results are given as the mean value of three replicates and presented as $\log \mathrm{cfu} / \mathrm{ml}$. Results are presented in graphic form.

In vitro survival in gastric and intestinal environment. Activated cells were harvested by centrifugation at $3000 \times \mathrm{g}$ for $10 \mathrm{~min}$ and inoculated at the level $10^{6} \mathrm{cfu} / \mathrm{ml}$ in a simulated gastric environment aqueous solution containing $3 \mathrm{~g} / \mathrm{l}$ pepsin $(3260 \mathrm{U} / \mathrm{mg})$ and $5 \mathrm{~g} / \mathrm{l}$ $\mathrm{NaCl}, \mathrm{pH} 2.0$ (Charteris et al., 1998). Yeast cultures were also inoculated into medium reproducing human intestine conditions, constituted by an aqueous solution containing $1 \mathrm{~g} / \mathrm{l}$ pancreatin $(903 \mathrm{U} / \mathrm{mg})$ and $5 \mathrm{~g} / \mathrm{l}$ $\mathrm{NaCl}, \mathrm{pH}$ 8.0. The cell viability was determined by the count plate method after $20,40,60,120,180$ and 240 minutes of incubation at $37^{\circ} \mathrm{C}$. The results are given as the mean value of three replicates and presented as percentage log survival (Williamson and Johnson, 1981).

Growth at 28 and $37^{\circ} \mathrm{C}$. Growth at different temperatures was estimated by inoculating $\left(10^{6} \mathrm{cfu} / \mathrm{ml}\right)$ activated cultures into YPD liquid medium. The samples were incubated at 28 and $37^{\circ} \mathrm{C}$ for 48 hours and the number of cells was determined by the count plate method. In order to compare growth curves the Gompertz equation in conjuction with DMFit program was used (Baranyi and Roberts, 1994). The Gompertz parameter values (A, B, C, M) were used to calculate exponential growth rates EGRs, generation times GTs, lag phase durations LPDs as described by Zaika et al. (1998).

Statistical analysis. Results were analysed using 3 -way ANOVA at the confidence level of $p<0.05$. Results of the population viability were presented as the arithmetic mean of three assays with standard deviation not exceeding 0.2 logarithmic units.

\section{Results}

Fecal and kefir isolates were identified as Saccharomyces cerevisiae according to their morphological characteristics, ability to assimilate carbon and nitrogen compounds and sugar fermentation patterns (data not shown). On the basis of karyotypes the tested strains were classified to the genus Saccharomyces, since they show 11-12 bands of a size varying between 200 and $2.300 \mathrm{~kb}$ (Fig. 1). There were differences in both the number and length of bands in electrophoregram of yeast S10-S12 chromosomal DNA. The fecal isolate S10 and one of the kefir strain S11 showed 


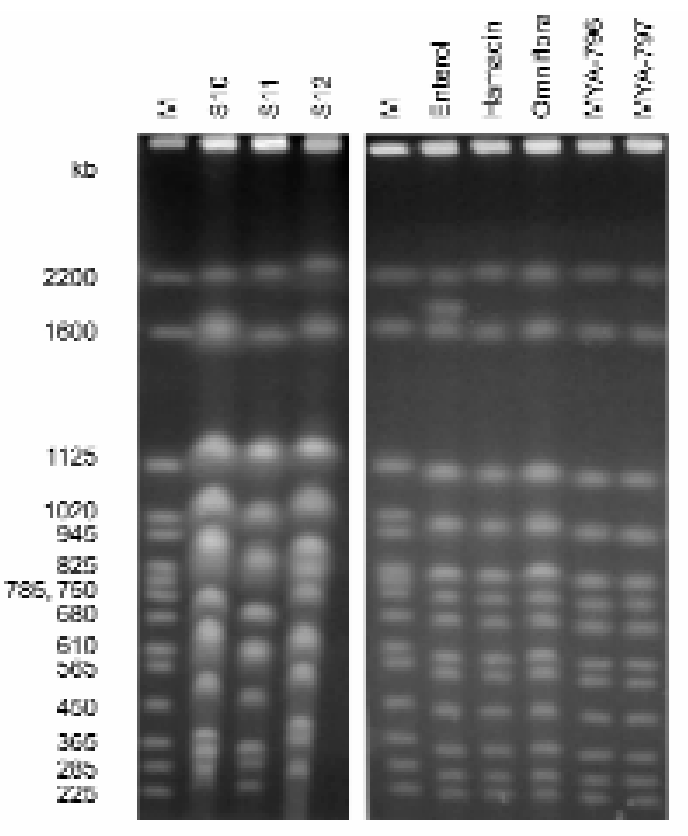

Fig. 1. Electrophoretic patterns of yeast chromosomal DNA M - marker S. cerevisiae YNN295 (Bio-Rad)

11 bands whereas the other strain derived from kefir S12 had 12 chromosomes. The electrophoretic patterns confirmed that probiotic and collection yeasts belong to the genus Saccharomyces. The chromosomal patterns of four S. cerevisiae var. boulardii strains (Hamadin ${ }^{\circledR}$, Omniflora $^{\circledR}$, MYA-796, MYA-797) did not show polymorphism and consisted of 13 bands sized 222-2251 kb (Fig. 1). Only the karyotype of the probiotic strain isolated from Enterol ${ }^{\circledR}$ was distinctive with additional chromosome $1884 \mathrm{~kb}$.

The yeasts were characterized by high adaptation to conditions of the human gastrointestinal tract. The survival of all tested strains in medium of $\mathrm{pH} 2.5$ was comparable and equaled $86.8-97.1 \%$ after 8 hours of incubation at $37^{\circ} \mathrm{C}$ (Table I). Decrease in $\mathrm{pH}$ to 1.5 led to further reduction in cell viability and the survival was $85.3-92.1 \%$ in the case of fecal, probiotic and collection strains. The kefir isolates showed higher sensitivity to $\mathrm{pH} 1.5$ and their survival was 33.1 and $38.9 \%$ after 8 hours of incubation.

Fecal and kefir isolates as well as probiotic and collection strains demonstrated high resistance to bile salts. The addition of 0.1 and $1.0 \%$ ox bile did not restrict viability of microorganisms (Fig. 2). In medium with $1.0 \%$ synthetic bile salts reduction of cell numbers by $1 \log$ unit after four hours of incubation was observed for the fecal isolate $\mathrm{S} 10$, probiotic and collection yeasts. The least bile salts tolerant were kefir

Table I

Percentage survival of yeasts at low $\mathrm{pH}$

\begin{tabular}{|c|c|c|c|c|c|c|c|c|c|c|c|c|}
\hline \multirow{3}{*}{ Strain } & \multicolumn{6}{|c|}{ pH 2.5} & \multicolumn{6}{|c|}{$\mathrm{pH} 1.5$} \\
\hline & \multicolumn{12}{|c|}{ Incubation time $[\mathrm{h}]$} \\
\hline & 1 & 2 & 3 & 4 & 6 & 8 & 1 & 2 & 3 & 4 & 6 & 8 \\
\hline S10 & 99.6 & 99.1 & 98.3 & 98.0 & 97.4 & 97.1 & 98.8 & 96.1 & 95.8 & 94.6 & 93.3 & 92.1 \\
\hline S11 & 99.5 & 98.8 & 97.3 & 95.3 & 90.8 & 86.8 & 85.9 & 70.0 & 58.8 & 56.5 & 47.6 & 38.9 \\
\hline S12 & 99.6 & 97.8 & 96.6 & 95.0 & 91.3 & 87.7 & 77.2 & 64.6 & 57.5 & 50.0 & 41.6 & 33.1 \\
\hline Enterol $^{\circledR}$ & 98.8 & 98.3 & 97.4 & 97.0 & 96.5 & 96.3 & 99.0 & 97.0 & 95.2 & 92.4 & 87.4 & 85.3 \\
\hline $\operatorname{Hamadin}^{\circledR}$ & 99.3 & 98.5 & 97.8 & 97.4 & 97.2 & 97.0 & 99.3 & 98.3 & 97.0 & 94.1 & 92.1 & 90.8 \\
\hline Omniflora $^{\circledR}$ & 99.8 & 99.3 & 98.9 & 98.4 & 97.4 & 95.4 & 98.5 & 97.6 & 96.6 & 94.9 & 91.6 & 87.4 \\
\hline MYA-796 & 99.4 & 98.8 & 98.5 & 98.2 & 97.7 & 96.7 & 98.5 & 97.4 & 95.2 & 93.0 & 90.4 & 87.4 \\
\hline MYA-797 & 99.7 & 99.2 & 98.2 & 97.8 & 97.4 & 97.0 & 98.6 & 97.0 & 95.4 & 93.7 & 88.8 & 87.5 \\
\hline
\end{tabular}

Table II

Percentage survival of yeasts in simulated gastric and intestinal environment

\begin{tabular}{|c|c|c|c|c|c|c|c|c|c|c|c|c|}
\hline \multirow{3}{*}{ Strain } & \multicolumn{6}{|c|}{ Gastric juice } & \multicolumn{6}{|c|}{ Intestine } \\
\hline & \multicolumn{12}{|c|}{ Incubation time [min] } \\
\hline & 20 & 40 & 60 & 120 & 180 & 240 & 20 & 40 & 60 & 120 & 180 & 240 \\
\hline $\mathrm{S} 10$ & 99.6 & 98.9 & 98.2 & 93.4 & 88.2 & 86.6 & 99.7 & 99.4 & 98.9 & 97.9 & 97.0 & 93.7 \\
\hline S11 & 99.5 & 97.9 & 96.1 & 88.6 & 83.5 & 75.5 & 98.8 & 97.7 & 97.0 & 93.5 & 87.1 & 83.1 \\
\hline S12 & 98.8 & 97.9 & 96.5 & 89.3 & 84.0 & 76.0 & 98.7 & 97.9 & 97.0 & 92.6 & 87.4 & 84.9 \\
\hline Enterol $^{\circledR}$ & 99.4 & 98.9 & 98.3 & 94.4 & 89.6 & 86.3 & 99.9 & 99.7 & 99.3 & 97.7 & 94.7 & 92.6 \\
\hline Hamadin $^{\circledR}$ & 99.7 & 99.4 & 99.2 & 97.6 & 93.5 & 88.5 & 99.9 & 99.8 & 99.7 & 99.1 & 98.4 & 97.3 \\
\hline Omniflora $^{\circledR}$ & 99.7 & 99.5 & 98.8 & 97.6 & 95.7 & 93.0 & 99.0 & 98.8 & 98.7 & 97.2 & 96.0 & 94.1 \\
\hline MYA-796 & 99.5 & 99.1 & 98.7 & 97.5 & 95.8 & 93.2 & 99.6 & 99.3 & 99.1 & 98.3 & 97.5 & 96.4 \\
\hline MYA-797 & 99.7 & 99.3 & 99.1 & 96.9 & 93.3 & 88.4 & 99.8 & 99.7 & 99.5 & 98.5 & 96.2 & 94.8 \\
\hline
\end{tabular}



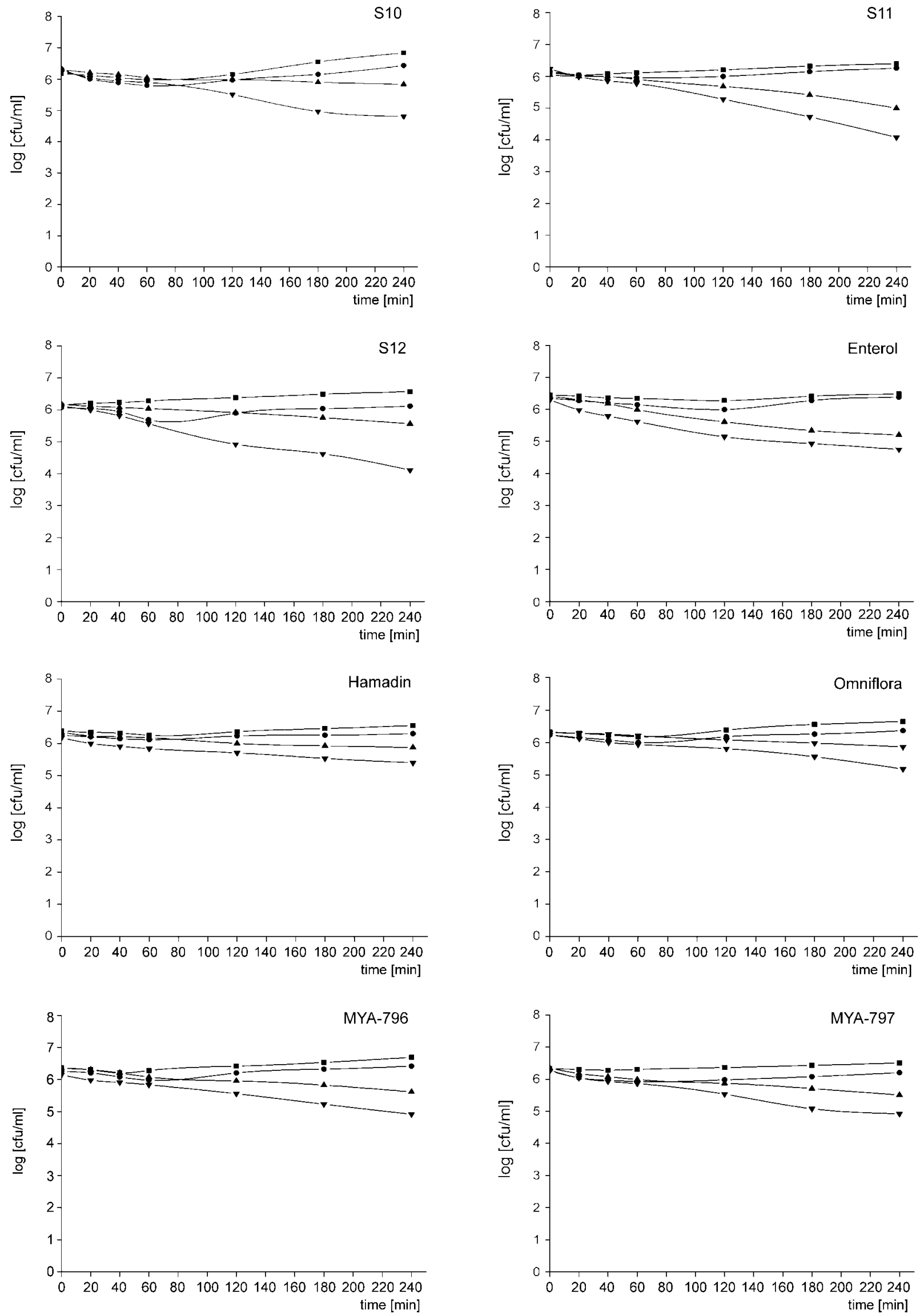

Fig. 2. Viability of yeasts in the presence of ox gall and bile salts.

$-1 \%$ ox gall,

$-0.1 \%$ synthetic bile salts, $-\boldsymbol{\nabla}-1 \%$ synthetic bile salts 
Table III

Gompertz equation parameters and derived growth kinetics values for yeast at different temperatures

\begin{tabular}{|c|c|c|c|c|c|c|c|c|}
\hline \multirow{2}{*}{ Strain } & \multirow{2}{*}{$\begin{array}{c}\text { Temperature } \\
{\left[{ }^{\circ} \mathrm{C}\right]}\end{array}$} & \multicolumn{4}{|c|}{ Gompertz parameters } & \multirow{2}{*}{$\begin{array}{c}\text { EGR } \\
{[(\log \mathrm{cfu} / \mathrm{ml}) / \mathrm{h}]}\end{array}$} & \multirow{2}{*}{$\mathrm{GT}[\mathrm{h}]$} & \multirow{2}{*}{$\mathrm{LPD}[\mathrm{h}]$} \\
\hline & & A & $\mathrm{C}$ & B & M & & & \\
\hline \multirow[t]{2}{*}{ S10 } & 28 & 6.45 & 7.89 & 0.0157 & 10.25 & 0.194 & 0.66 & 3.89 \\
\hline & 37 & 6.51 & 7.77 & 0.0592 & 16.88 & 0.169 & 1.78 & 1.41 \\
\hline \multirow[t]{2}{*}{ S11 } & 28 & 6.64 & 7.85 & 0.0637 & 19.74 & 0.184 & 1.64 & 4.04 \\
\hline & 37 & 6.68 & NG & - & - & - & - & - \\
\hline \multirow[t]{2}{*}{ S12 } & 28 & 6.72 & 7.92 & 0.0531 & 22.98 & 0.154 & 1.94 & 4.16 \\
\hline & 37 & 6.65 & NG & - & - & - & - & - \\
\hline \multirow[t]{2}{*}{ Enterol $^{\circledR}$} & 28 & 6.57 & 7.96 & 0.0664 & 18.61 & 0.194 & 1.55 & 3.54 \\
\hline & 37 & 6.61 & 7.35 & 0.0339 & 31.28 & 0.092 & 3.28 & 1.84 \\
\hline \multirow[t]{2}{*}{$\operatorname{Hamadin}^{\circledR}$} & 28 & 6.59 & 8.20 & 0.0759 & 16.69 & 0.229 & 1.31 & 3.53 \\
\hline & 37 & 6.63 & 7.73 & 0.0548 & 21.07 & 0.156 & 1.93 & 2.83 \\
\hline \multirow[t]{2}{*}{ Omniflora $^{\circledR}$} & 28 & 6.59 & 8.20 & 0.0897 & 14.89 & 0.269 & 1.12 & 3.73 \\
\hline & 37 & 6.64 & 7.73 & 0.1053 & 13.17 & 0.287 & 1.05 & 3.68 \\
\hline \multirow[t]{2}{*}{ MYA-796 } & 28 & 6.53 & 7.92 & 0.0817 & 16.09 & 0.238 & 1.27 & 3.85 \\
\hline & 37 & 6.59 & 7.82 & 0.0896 & 13.30 & 0.258 & 1.17 & 2.13 \\
\hline \multirow[t]{2}{*}{ MYA-797 } & 28 & 6.44 & 7.98 & 0.0736 & 17.73 & 0.216 & 1.40 & 4.14 \\
\hline & 37 & 6.42 & 7.47 & 0.0625 & 19.94 & 0.172 & 1.75 & 3.95 \\
\hline
\end{tabular}

$\mathrm{NG}$ - no growth

yeasts (S11 and S12) but even their populations decreased by only $2 \log$ units in the course of experiment.

In simulated gastric and intestinal environment the survival of all tested yeasts equaled $75.5-93.2 \%$ and $83.1-97.3 \%$ after 4 hours of incubation in media with pepsin and pancreatin, respectively (Table II). It was found that the fecal isolate S10, probiotic and collection yeasts expressed comparable tolerance to the presence of gastrointestinal enzymes and the differences among strains amounted to less than 7\%. Compared to these yeasts the kefir isolates S11 and S12 were more affected by exposure to the enzymes and the low $\mathrm{pH}$. It seems that factor which stronger restricted the viability of yeasts was $\mathrm{pH}$, much lower in medium reproducing conditions in human stomach than in human intestine.

The fecal isolate $\mathrm{S} 10$, the probiotic yeasts and the collection strains were able to grow at $37^{\circ} \mathrm{C}$. In most cases decrease in the rate of growth and lower yield compared to the growth at optimal temperature $28^{\circ} \mathrm{C}$ were noted (Table III). Interestingly, except for the probiotic Omniflora ${ }^{\circledR}$ strain, $42-80 \%$ shortening of lag phase was observed at $28^{\circ} \mathrm{C}$. The kefir isolates $\mathrm{S} 11$ and S12 were incapable of growth at $37^{\circ} \mathrm{C}$, but nevertheless their survival after 48 hours of incubation at $37^{\circ} \mathrm{C}$ was $92.5 \%$.

\section{Discussion}

On the basis of chromosomal patterns the kefir and fecal isolates were identified as Saccharomyces spp. and the classification of probiotic and collection strains to the genus Saccharomyces was confirmed. Similar results were obtained for dozens of yeasts belonging to Saccharomyces sensu stricto group (Cardinali and Martini, 1994; Naumov et al., 2001; Vaughan-Martini et al., 1993). However, positive yeast identification at the species level is very difficult because of chromosomal length polymorphism (Fietto et al., 2004; Naumov et al., 2001; Pataro et al., 2000). VaughanMartini et al. (1993) concluded that none of the species of genus Saccharomyces could be distinguished by the consistent presence or absence of a unique band or cluster of bands. Some taxonomic studies (Mitterdorfer et al., 2002; Van der Aa Kühle et al., 2001) have indicated that $S$. boulardii should be considered as a strain of $S$. cerevisiae. This conclusion was confirmed by analysis of DNA polymorphism (Molnar et al., 1995) and reports of 95\% DNA homology between $S$. cerevisiae and S. boulardii (Vaughan-Martini and Martini, 1987). These findings are reflected in current nomenclature and according to the International Code of Botanical Nomenclature strains S. boulardii comprise the subtype of the $S$. cerevisiae species and should be referred as $S$. cerevisiae var. boulardii.

Interestingly, in several studies no variations in the genotype of S. cerevisiae var. boulardii have been observed (Cardinali and Martini, 1994; Hannequin et al., 2001; Malgoire et al., 2005; McFarland, 1996), which is in disagreement with the results of present work. Recently, Klingberg et al. (2008) found that probiotic strains isolated from medicines Levucell ${ }^{\circledR} \mathrm{SB}$ and Precosa ${ }^{\circledR}$ had identical profiles but clustered together with the probiotic isolates get from UltraLevure $^{\circledR}$ at a similarity of about $90 \%$. 
Most definitions of probiotics emphasize that the microorganisms should be viable and reach their site of action alive (Ouwehand et al., 1999). The primary barrier in the stomach is the gastric acid of inhibitory action being related to low $\mathrm{pH}$ and enzyme presence. All the tested yeasts showed high tolerance to these conditions, however kefir isolates were more sensitive than the probiotic, collection and fecal strains. It seems that the factor which could influence stronger the growth of yeasts was $\mathrm{pH}$. There were significant differences between yeast survival in medium of $\mathrm{pH} 2.5$ and 1.5 for food-borne isolates S11 and S12 (47.9 and $54.6 \%$, respectively). Normal values for human gastric $\mathrm{pH}$ are 1-3 fasting and up to 5 after a meal (Cummings et al., 2004) and average stomach transit time is 2.5-4 hours (Camilleri et al., 1989). We assumed stricter conditions in our investigation and examined yeasts survival during 8 hours of incubation in medium of very low $\mathrm{pH}$. In these harsh conditions sufficient viable cells of all the tested strains could enter the small intestine indicating the possibility of their survival and proper activity in the human intestine.

Besides tolerance to acid conditions, all the tested yeasts demonstrated the ability to withstand $1.0 \%$ ox gall. Similar results have been reported previously for $S$. cerevisiae strains isolated from infant feces, feta cheese and beverages (Psomas et al., 2001; Van der Aa Kühle et al., 2005). Bile tolerance is important for allowing a microorganism to survive in the intestinal tract (Gilliland et al., 1984).

Growth at $37^{\circ} \mathrm{C}$ seems to be a variable characteristic of $S$. cerevisiae (Barnett et al., 2000). In this study the fecal isolate $\mathrm{S} 10$, all probiotic and collection yeasts were able to grow at this temperature, in contrast to two strains isolated from kefirs. Nevertheless, the survival of these strains equaled $97.9 \%$ for S11 and $86.9 \%$ for $\mathrm{S} 12$ after 48 hours of incubation at $37^{\circ} \mathrm{C}$.

Generally, isolates from feces, probiotic strains derived from medications and collection strains are able to grow at the temperature of $37^{\circ} \mathrm{C}$ and tolerate better the low $\mathrm{pH}$, presence of gastrointestinal enzymes and bile salts than kefir yeasts. This finding is consistent with the conclusion of the importance of yeast origins for probiotic properties (Ouwehand et al., 1999). However, irrespective of strain origins, all the tested yeasts may survive passage throughout the upper gastrointestinal tract and be viable at their sites of action in the gut environment.

The results of the present study suggest that all tested yeasts may survive in the human gastrointestinal tract and thus create the possibility of proper activity in the human body.

\section{Acknowledgments}

This research was supported by the State Committee for Scientific Research as a grant No N312 043 32/2614.

\section{Literature}

Baranyi J. and T.A. Roberts. 1994. A dynamic approach to predicting bacterial growth in food. Int. J. Food Microbiol. 23: 277-294.

Barnett J.A., R.W. Payne and D. Yarrow. 2000. Yeasts: characteristics and identification. $3^{\text {rd }}$ ed. Cambridge University Press, Cambridge, UK

Camilleri M., L.J. Colemont, S.F. Phillips, M.L. Brown, G.M. Thomforde, N. Chapman and A.R. Zinsmeister. 1989. Human gastric emptying and colonic filling of solids characterized by a new method. Am. J. Physiol. Gastrointest. Liver Physiol. 257: 284-290.

Cardinali G. and A. Martini. 1994. Electrophoretic karyotypes of authentic strains of the sensu stricto group of the genus Saccharomyces. Int. J. Syst. Bacteriol. 44: 791-797.

Charteris W.P., P.M. Kelly, L. Morelli and J.K. Collins. 1998. Development and application of an in vitro methodology to determine the transit tolerance of potentially probiotic Lactobacillus and Bifidobacterium species in the upper human gastrointestinal tract. J. Appl. Microbiol. 84: 759-768.

Conway P.L. 1996. Selection criteria for probiotic microorganisms. Asia Pacific J. Clin. Nutr. 5: 10-14.

Cummings J.H., J.M. Antoine, F. Azpiroz, R. Bourdet-Sicard, P. Brandtaeg, P.C. Calder, G.R. Gibson, F. Guarner, E. Isolauri, D. Pannemans and others. 2004. Passclaim - gut health and immunity. Eur. J. Nutr. 43 (Suppl 2): 118-173.

Edwards-Ingram L.C., M.E. Gent, D.C. Hoyle, A. Hayes, L.I. Stateva and S.G. Oliver. 2004. Comparative genomic hybridization provides new insights into the molecular taxonomy of the Saccharomyces sensu stricto complex. Genome Res. 14: 1043-1051.

Fietto J.L.R., R.S. Araujo, F.N. Valadao, L.G. Fietto, R.L. Brandao, M.J. Neves, F.C.O. Gomes, J.R. Nicoli and I.M. Castro. 2004. Molecular and physiological comparisons between Saccharomyces cerevisiae and Saccharomyces boulardii. Can. J. Microbiol. 50: 615-621.

Fooks L.J. and G.R. Gibson. 2002. Probiotics as modulators of the gut flora. Br. J. Nutr. 88 (Suppl. 1): 39-49.

Gilliland S.E., T.E. Stanley and L.J. Bush. 1984. Importance of bile tolerance of Lactobacillus acidophilus used as a dietary adjunct. J. Dairy Sci. 67: 3045-3051.

Hannequin C., A. Thierry, G.F. Richard, G. Lecointre, H.V. Nguyen, C. Gaillardin and B. Dujon. 2001. Microsatellite typing as a new tool for identification of Saccharomyces cerevisiae strains. J. Clin. Microbiol. 39: 551-559.

Klingberg T.D., U. Lesnik, N. Arneborg, P. Raspor and L. Jespersen. 2008. Comparison of Saccharomyces cerevisiae strains of clinical and nonclinical origin by molecular typing and determination of putative virulence traits. FEMS Yeast Res. 8: 631-640.

Liti G., D.B.H. Barton and E.J. Louis. 2006. Sequence diversity, reproductive isolation and species concepts in Saccharomyces. Genetics 174: 839-850.

Malgoire J.Y., S. Bertout, F. Renaud, J.M. Bastide and M. Mallie. 2005. Typing of Saccharomyces cerevisiae clinical strains by using microsatellite sequence polymorphism. J. Clin. Microbiol. 43: 1133-1137.

McFarland L.V. 1996. Saccharomyces boulardii is not Saccharomyces cerevisiae. Clin. Infect. Dis. 22: 200-201.

McFarland L.V. and P. Bernasconi. 1993. Saccharomyces boulardii: a review of an innovative biotherapeutic agent. Microb. Ecol. 6: 157-171. 
Mitterdorfer G., H.K. Mayer, W. Kneifel and H. Viernstein. 2002. Clustering of Saccharomyces boulardii strains within the species Saccharomyces cerevisiae using molecular typing techniques. J. Appl. Microbiol. 18: 521-530.

Molnar O., R. Messner, H. Prillinger, U. Stahl and E. Slavikova. 1995. Genotypic identification of Saccharomyces species using random amplified polymorphic DNA analysis. Syst. Appl. Microbiol. 18: 136-145.

Naumov G.I., H.V. Nguyen, E.S. Naumova, V. Michel, M. Aigle and C. Gaillardin. 2001. Genetic identification of Saccharomyces bayanus var. uvarum, a cider fermenting yeast. Int. J. Food Microbiol. 65: 163-171.

Ouwehand A.C., P.V. Kirjavainen, C. Shortt and S. Salminen. 1999. Probiotics: mechanisms and established effects. Int. Dairy J. 9: 43-52.

Ouwehand A.C., S. Salminen and E. Isolauri. 2002. Probiotics: an overview of beneficial effects. Antonie Leeuwenhoek 82: 279-289.

Pataro C., J.B. Guerra, M.L. Petrillo-Peixoto, L.C. MendoncaHagler, V.R. Linardi and C.A. Rosa. 2000. Yeast communities and genetic polymorphism of Saccharomyces cerevisiae strains associated with artisanal fermentation in Brazil. J. Appl. Microbiol. 88: 1-9. Psomas E., C. Andrighetto, E. Litopoulou-Tzanetaki, A. Lombardi and N. Tzanetakis. 2001. Some probiotic properties of yeast isolates from infant feces and Feta cheese. Int. I. Food Microbiol. 69 (1): 125-133.
Schwartz D.C. and C.R. Cantor. 1984. Separation of yeast chromosome-sized DNAs by pulsed field gradient gel electrophoresis. Cell 37: 67-75.

Van der Aa Kühle A., L. Jespersen, R.L.K. Glover, B. Diawara and M. Jakobsen. 2001. Identification and characterization of Saccharomyces cerevisiae strains from West Africa sorghum beer Yeast 18: 1069-1079.

Van der Aa Kühle A., K. Skovgaard and L. Jespersen. 2005. In vitro screening of probiotic properties of Saccharomyces cerevisiae var. boulradii and food-borne Saccharomyces cerevisiae strains. Int. J. Food Microbiol. 101: 29-39.

Vaughan-Martini A. 2003. Reflections on the classification of yeasts for different end-users in biotechnology, ecology and medicine. Int. Microbiol. 6: 175-182.

Vaughan-Martini A. and A. Martini. 1987. Three newly delimited species of Saccharomyces sensu stricto. Antonie Leeuwenhoek 53: 77-84.

Vaughan-Martini A., A. Martini and G. Cardinali. 1993 Electrophoretic karyotyping as a taxonomic tool in the genus Saccharomyces. Antonie Leeuwenhoek 63: 145-156.

Williamson K.J. and O.G. Johnson. 1981. A bacterial assay for assessment of wastewater toxicity. Water. Res. 15: 383-390.

Zaika L.L., J.G. Philips, J.S. Fanelli and O.J. Scullen. 1998. Revised model for aerobic growth of Schigella flexneri to extend the validity of predictions at temperatures between 10 and $19^{\circ} \mathrm{C}$. Int. J. Food Microbiol. 41: 9-19. 